\title{
Research on Microwave-Assisted Catalytic Persulfate Technology in the Field of Environmental Energy
}

\author{
Hongzhu $\mathrm{Xu}^{1, \mathrm{a}}$, Changbo $\mathrm{Li}^{1 *}$, Shuo Wang ${ }^{1}$, Guozheng Zhao ${ }^{1}$, Hui Liang ${ }^{1}$, Yuting $\mathrm{Fu}^{1}$ \\ ${ }^{1}$ School of Environmental and Safety Engineering, Liaoning Petrochemical University, Fushun, Liaoning, 113001, China
}

\begin{abstract}
Catalytic persulfate technology is a new type of catalytic technology that has been extensively studied in recent years. Among them, the new copper and silver materials synthesized by microwave assist have broad application prospects and are a class of catalysts with excellent performance, environmental friendliness, and stable structure. This article introduces a new type of material loaded with metal copper and silver and activated carbon, analyzes the mechanism of catalytic oxidation, and focuses on summarizing the influencing factors, degradation mechanism, and potential pollutant degradation pathways of this new type of material in water treatment.
\end{abstract}

\section{Introductio}

Advanced oxidation processes (AOPs) based on persulfate are often used to remove difficult-to-degrade organic pollutants in water. The catalytic persulfate system generates PMS and peroxodisulfate (PDS) by decomposing persulfate, which can efficiently remove organic matter under milder conditions[1-3]. PMS makes $\mathrm{SO}_{4}{ }^{--}$more easily activated than $\cdot \mathrm{OH}$ due to its special structure. The oxidation-reduction cycle between $\mathrm{Cu}(\mathrm{II}) / \mathrm{Cu}$ (I) makes it have a higher degradation rate of organic matter, but the slow conversion rate leads to lower catalytic efficiency[4]. On this basis, we combined $\mathrm{Cu}-\mathrm{Ag}$ bimetal and $\mathrm{Ac}$ to prepare $\mathrm{Cu}-\mathrm{Ag} / \mathrm{Ac}$ composites and confirmed that it has highly efficient degradation properties. The structural characteristics and catalytic performance of the catalyst were studied, the reaction mechanism of the catalytic persulfate system and the degradation pathway of pollutants were explored, and the influence of various factors on the $\mathrm{Cu}-\mathrm{Ag} / \mathrm{Ac}$ persulfate catalytic system was evaluated.

\section{Experimental method}

\subsection{Preparation of $\mathrm{Cu}-\mathrm{Ag} / \mathrm{Ac}$ composite material}

Dissolve $0.2 \mathrm{~mol} / \mathrm{L}$ of $\mathrm{Cu}\left(\mathrm{NO}_{3}\right)_{2} \cdot 3 \mathrm{H}_{2} \mathrm{O}$ and $0.4 \mathrm{~mol} / \mathrm{L}$ of $\mathrm{AgNO}_{3}$ in $200 \mathrm{~mL}$ of deionized water, weigh $5 \mathrm{~g}$ of powdered activated carbon into the above-mixed solution, stir well and let it stand $3 \mathrm{~h}$ standby so that the active components of $\mathrm{Cu}$ and $\mathrm{Ag}$ reach saturation on Ac. Add $5 \mathrm{~g}$ of triblock polymer F127 and $8 \mathrm{~mL}$ of ethanol to the

$\overline{{ }^{a} E-m a i l: ~ 528279887 @ q q . c o m ~}$

*Corresponding author's e-mail: lichangbo@lnpu.edu.cn mixture, then put it into a high-throughput microwave digestion apparatus, and set it at $700 \mathrm{~W}$ After reacting with $373 \mathrm{~K}$ for $120 \mathrm{~min}$, and $500^{\circ} \mathrm{C}$ muffle furnace was calcined for $3 \mathrm{~h}$, then removed and ground to obtain a composite Material $\mathrm{Cu}-\mathrm{Ag} / \mathrm{Ac}$.

\subsection{Catalytic performance test}

A $100 \mathrm{mg} / \mathrm{L}$ simulated phenol solution was prepared as a stock solution and stored in a refrigerator at $4^{\circ} \mathrm{C}$. When using, pipette an appropriate volume of phenol solution into a beaker, add $\mathrm{Cu}-\mathrm{Ag} / \mathrm{Ac}$ and $\mathrm{K}_{2} \mathrm{~S}_{2} \mathrm{O}_{8}$ and stir well for $30 \mathrm{~min}$, then transfer to the digestion tank, microwave power $700 \mathrm{~W}$, investigate the variable reaction temperature, initial $\mathrm{pH}$, reaction time, $\mathrm{Cu}-\mathrm{Ag}$ The influence of the amount of $/ \mathrm{Ac}$ and $\mathrm{K}_{2} \mathrm{~S}_{2} \mathrm{O}_{8}$ on the catalytic persulfate system, the solution was taken out during different reaction times to measure the COD and phenol concentration.

\subsection{Analysis method}

The phenol content was determined by the 4aminoantipyrine method, and the absorbance of the solution at $270 \mathrm{~nm}$ was taken within a certain period of time.

\section{Results and discussion}

\subsection{The effect of reaction conditions on the degradation of phenol}

3.1.1. Initial $\mathrm{pH}$. The initial $\mathrm{pH}$ affects the activation of 
persulfate and the existence of pollutants in the aqueous solution, and then different reaction processes occur. Figure 1a and $1 \mathrm{~b}$ show the degradation rates of COD and phenol at $\mathrm{pH} 3-11$, respectively. It can be seen that the removal effect is better under lower or higher $\mathrm{pH}$ conditions; the effect under acidic conditions is better than neutral and alkaline conditions. At $\mathrm{pH}=4$, The removal rate of COD and phenol after $30 \mathrm{~min}$ is $79.8 \%$ and $46.4 \%$; the degradation rate of phenol increases by $30 \%$ after the reaction is carried out for 60 minutes, which indicates that there is more $\mathrm{SO}_{4}{ }^{-}$in the solution, which speeds up the reaction rate. When $\mathrm{pH}<3$, the reaction effect is significantly reduced, and the PMS in the system is converted to $\mathrm{HS}_{2} \mathrm{O}_{8}{ }^{2-}$, and then $\mathrm{S}_{2} \mathrm{O}_{4}{ }^{2-}$ and bisulfate are generated. So far, there is only a small amount of $\mathrm{SO}_{4}{ }^{-}$in the reaction, so the degradation rate is greatly reduced, and the result only shows The performance of a single catalyst.

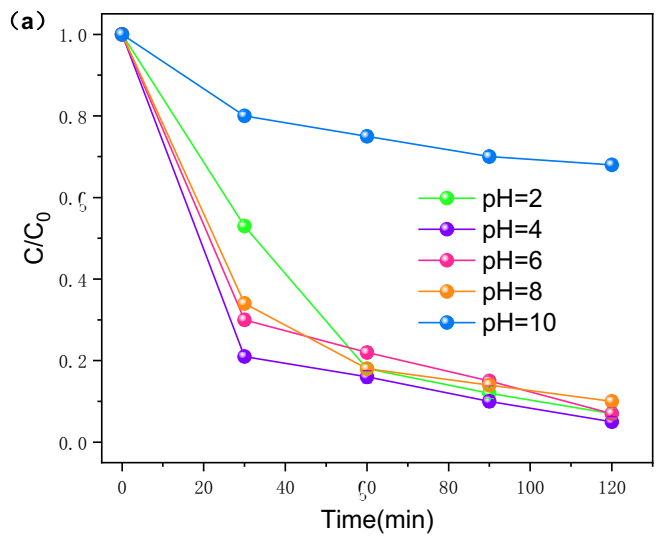

According to the research of Chenju Liang et al., $\mathrm{SO}_{4}$ dominates at a $\mathrm{pH}$ close to neutral; at $\mathrm{pH}=9$, both $\mathrm{SO}_{4}$ and $\cdot \mathrm{OH}$ exist; at alkaline $\mathrm{pH}$ and a $\mathrm{pH}$ close to 11 , The dominant gene is $\mathrm{OH}$. Continue to increase the $\mathrm{pH}$ to $10 \sim 11$. At this time, the $\mathrm{SO}_{4}-$ generated by the activation reacts with the $\mathrm{OH}^{-}$in the system to generate $\cdot \mathrm{OH}$. Its standard reduction potential is $2.7 \mathrm{~V}$ in acidic solution and $1.8 \mathrm{~V}$ in neutral solution. This can explain that the COD removal rate is only $30 \%$ when the reaction is carried out for 120 minutes. The higher the $\mathrm{pH}$ value, the weaker the oxidation capacity. Under alkaline conditions, $\mathrm{SO}_{4}{ }^{-}$has a significant inhibitory effect on $\mathrm{OH}^{-}$. As the reaction progresses, the $\mathrm{pH}$ in the solution drops rapidly and $\mathrm{H}^{+}$ increases, which promotes the formation of free radicals. In general, the reaction has a significant effect between $\mathrm{pH}$ $3 \sim 8$. According to the number of free radicals generated in the reaction, $\mathrm{pH}=4$ can be the best condition.

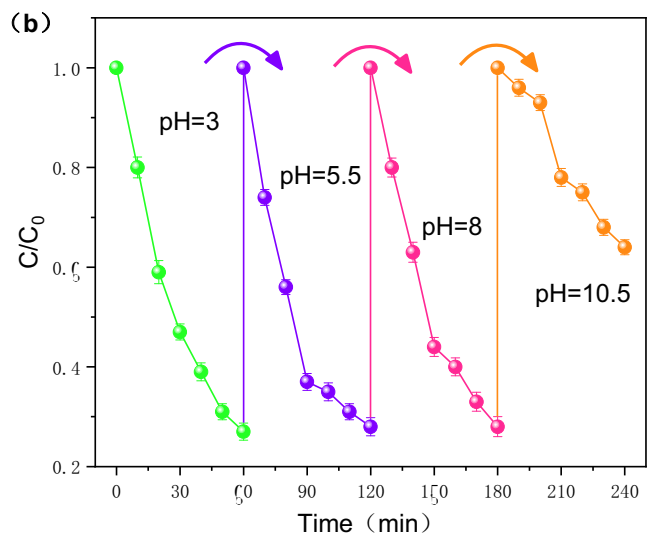

Figure 1. The effect of initial $\mathrm{pH}$ on the reaction

3.1.2. Inorganic anions. The anions in the solution will affect the degradation of the target product. In this experiment, the influence of different anions on free radicals in the system was investigated under $\mathrm{Cu}$ $\mathrm{Ag} / \mathrm{Ac}=1.5 \mathrm{~g} / \mathrm{L}$ and persulfate $=10 \mathrm{mmol} / \mathrm{L}$. Figure $2 \mathrm{a}$ shows that $\mathrm{Cl}^{-}$has an inhibitory effect on phenol, and the degradation rate of phenol has dropped from $89 \%$ to $65 \%$. The $\mathrm{Cl}^{-}$in the solution is quenched to produce $\mathrm{SO}_{4}{ }^{-}$to generate the less active free radicals $\mathrm{Cl}^{-}, \mathrm{Cl}_{2}{ }^{-}$and $\mathrm{HOCl}$.

$\mathrm{HCO}_{3}{ }^{-}$has a significant inhibitory effect on phenol

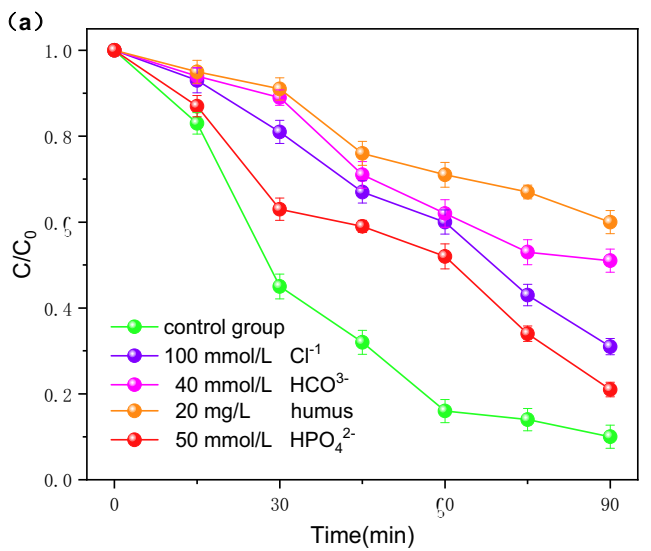

during the reaction for 90 minutes, showing a downward trend of $89 \%-46 \%$ (Figure $2 \mathrm{~b}$ ). $\mathrm{HCO}_{3}^{-}$is a free radical quencher and has a slow reaction rate with organics. It reacts slowly with organic matter and has a strong quenching effect on $\mathrm{SO}_{4}{ }^{-}$and $\mathrm{OH}^{-}$. Besides, the addition of $\mathrm{HPO}_{4}{ }^{2-}$ and humus also inhibited the degradation rate of phenol. Under the conditions of $50 \mathrm{mmol} / \mathrm{L} \mathrm{HPO}_{4}{ }^{2-}$ and $20 \mathrm{mg} / \mathrm{L}$ humus, the degradation rate of phenol decreased from $89 \%$ to $72 \%$ and $27 \%$ respectively. This may be due to the reaction of anions and free radicals to generate secondary free radicals with a slower reaction rate, which weakened the oxidation.

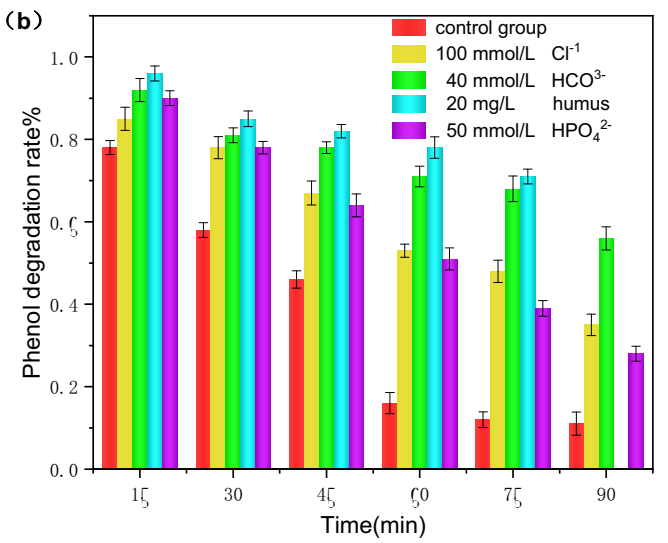

Figure 2. The influence of inorganic anions on the reaction 
3.1.3. Reaction temperature. Taking into account the feasibility in actual operation, this study will control the temperature between 0 and $120^{\circ} \mathrm{C}$ for experiments. It can be seen from the results that the temperature from 30 to $70{ }^{\circ} \mathrm{C}$ significantly improves the removal efficiency of COD, showing a removal rate of $74.4 \%$ to $93.0 \%$. PMS is catalyzed by $\mathrm{Cu}-\mathrm{Ag} / \mathrm{Ac}$ to generate highly active free radicals, which accelerates $\mathrm{S}_{2} \mathrm{O}_{8}{ }^{2-}$ decomposes into $\mathrm{SO}_{4}{ }^{--}$, which increases the solubility of organics in water and increases the number of intermolecular collisions; higher temperatures indirectly aggravate the concentration of $\mathrm{SO}_{4} \cdot-$ and $\cdot \mathrm{OH}$, and the temperature at $50 \sim 70^{\circ} \mathrm{C}$ is beneficial to $\mathrm{Cu}-\mathrm{Ag} / \mathrm{Ac}$ catalyzes the degradation of organic matter by PMS system. When the temperature was increased from $70^{\circ} \mathrm{C}$ to $120^{\circ} \mathrm{C}$, the COD removal rate dropped by $20 \%$, and the subsequent increase in the reaction time failed to improve the efficiency, which indicated that the system had a temperature threshold for $\mathrm{SO}_{4}{ }^{-}$. According to the experimental data, it is speculated that the dominant free radical that degrades organic matter is $\mathrm{SO}_{4}{ }^{-}$, not persulfuric acid or other anions. In summary, the degradation effect of COD and phenol is the best when the temperature is between 60 and $70^{\circ} \mathrm{C}$.

\subsubsection{PMS concentration and catalyst dosage. After} confirming that the $\mathrm{Cu}-\mathrm{Ag} / \mathrm{Ac}$ catalyzed PMS system effectively removes phenol, experiments were conducted to explore the influence of various factors.

The PMS concentration is shown in Figure 3a. The results show that increasing the PMS concentration from $2.5 \mathrm{mmol} / \mathrm{L}$ to $5.0 \mathrm{mmol} / \mathrm{L}$ can significantly improve the catalytic performance. However, due to the rapid consumption of PMS by $\mathrm{Cu}-\mathrm{Ag} / \mathrm{Ac}$, the catalytic performance is not ideal when the PMS concentration is

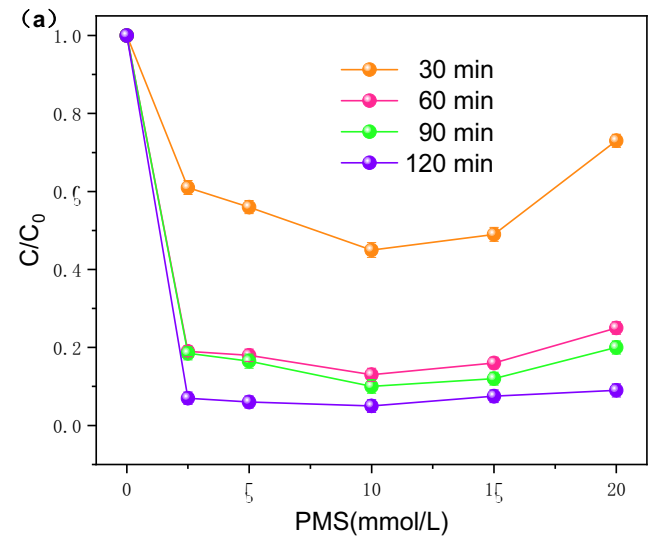

insufficient $(<5.0 \mathrm{mmol} / \mathrm{L})$. When it was increased to 10 $\mathrm{mmol} / \mathrm{L}$, the removal rate of phenol reached $85 \%$ after 60 minutes, and increasing the PMS concentration was beneficial to the degradation of organic matter. The concentration of PMS continues to increase, and the generated sulfate radicals decompose phenol molecules and promote double bond and electron transfer through $\mathrm{H}$ extraction. During the reaction process, PMS can directly react with phenol, and the generated $\mathrm{SO}_{4}{ }^{-}$attacks phenol molecules for a series of chain reactions, and finally decomposes organic matter. When its concentration is $>10$ $\mathrm{mmol} / \mathrm{L}$, the degradation rate of phenol is $80 \%$, and a large amount of $\mathrm{HSO}_{5}{ }^{-}$in the solution acts as an $\mathrm{SO}_{4}{ }^{-}$scavenger to generate $\mathrm{SO}_{5}{ }^{-}$and $\mathrm{SO}_{4}{ }^{2-}$ with weaker activation performance, which is free radicals mutually Nirvana reaction occurred between the formation of $\mathrm{S}_{2} \mathrm{O}_{8}{ }^{2-}$ making phenol degradation inhibited.

Considering the dual factors of performance and economy, combined with a practical point of view, it is unreasonable to further increase the PMS concentration to carry out the catalytic process. Therefore, it is determined that the PMS concentration of $10 \mathrm{mmol} / \mathrm{L}$ is the optimal reaction process condition.

Figure $3 \mathrm{~b}$ shows the effect of variable $\mathrm{Cu}-\mathrm{Ag} / \mathrm{Ac}$ dosage on degradation. The amount of $\mathrm{Cu}-\mathrm{Ag} / \mathrm{Ac}$ increased from $0.5 \mathrm{~g} / \mathrm{L}$ to $1.5 \mathrm{~g} / \mathrm{L}$, and the COD removal rate showed a trend of $30.2 \% \sim 81.3 \%$ after 60 minutes, which indicates that the active sites of PMS available in the system increase and produce more The active free radicals accelerate the decomposition of organic matter. Further increasing the catalyst dosage to $2.0 \mathrm{~g} / \mathrm{L}$ did not significantly increase the degradation rate of organic matter, but showed a downward trend, which indicates that more catalysts act as $\mathrm{SO}_{4}{ }^{-}$scavengers, making $\mathrm{Cu}-\mathrm{Ag} / \mathrm{Ac}$ catalyze active species in the PMS system Repressed. From an economic point of view, the best dosage of $\mathrm{Cu}$ $\mathrm{Ag} / \mathrm{Ac}$ is $1.5 \mathrm{~g} / \mathrm{L}$.

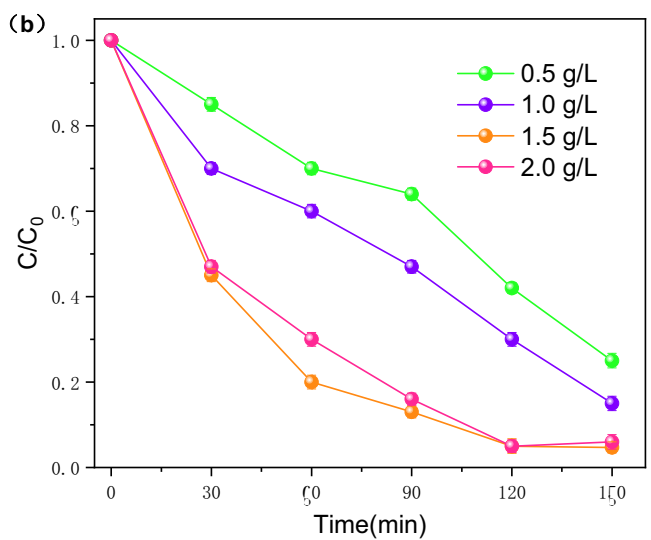

Figure 3. The influence of PMS concentration and time on the reaction

\subsection{Catalyst stability and free radical identification}

To verify the removal of free radicals in the phenol system by $\mathrm{Cu}-\mathrm{Ag} / \mathrm{Ac}$ catalyzed by persulfate, a free radical extinguishing experiment was carried out. When the reaction solution contains both free radicals, TBA will extinguish the $\cdot \mathrm{OH}$ reaction, keep $\mathrm{SO}_{4}{ }^{-}$. The reaction rate constants of ethanol (EtOH) and $\mathrm{SO}_{4}{ }^{-}$and $\cdot \mathrm{OH}$ are close, so $\mathrm{EtOH}$ will destroy both at the same time.

The COD decreased slightly when $100 \mathrm{mmol} / \mathrm{L}$ TBA was added to the system compared with the control group, 
indicating that the degradation of organic matter was not greatly affected by $\cdot \mathrm{OH}$; when $100 \mathrm{mmol} / \mathrm{L} \mathrm{EtOH}$ was added, the removal rate after 90 minutes of reaction The decrease from $90 \%$ to $60 \%$ indicates that the addition of EtOH inhibits the degradation of phenol, and $\mathrm{SO}_{4}{ }^{--}$plays a major role in oxidative degradation in the system. The concentration of EtOH and TBA was increased to 500 $\mathrm{mmol} / \mathrm{L}$, the COD removal rate after 90 minutes of the reaction was $35 \%$ and $46 \%$, respectively, and the total contribution rate of the two free radicals reached $81 \%$, which was mainly due to $\mathrm{Cu}-\mathrm{Ag} / \mathrm{Ac}$ The addition improves the ability of the catalytic system to activate PMS. The above results indicate that the active species in the system are $\cdot \mathrm{OH}$ and $\mathrm{SO}_{4}{ }^{-}$, of which $\mathrm{SO}_{4}{ }^{--}$plays a major role.

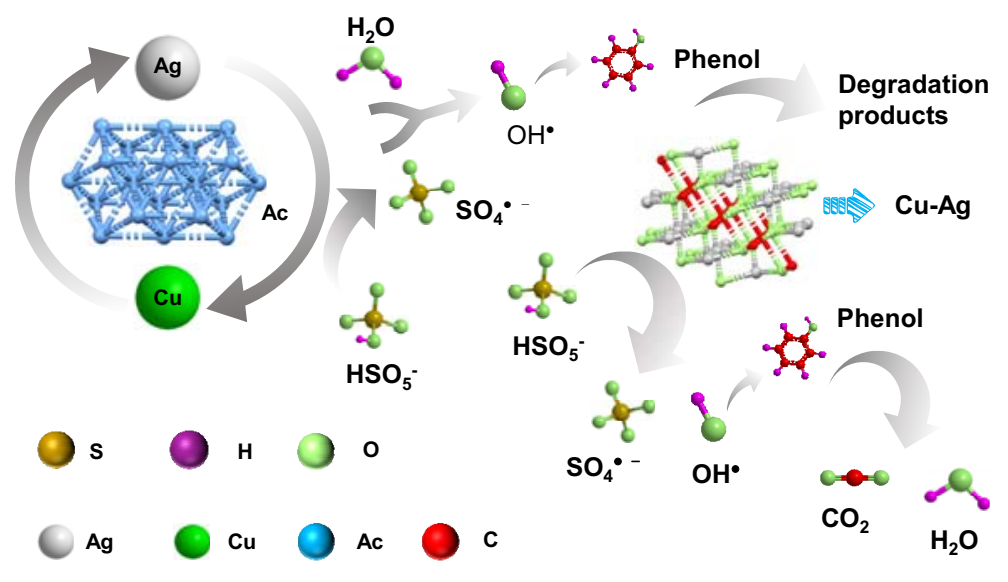

Figure 4. Research on reaction mechanism

\section{Results and discussion}

In this study, a bimetallic $\mathrm{Cu}-\mathrm{Ag} / \mathrm{Ac}$ material was synthesized by microwave-assisted synthesis. $\mathrm{Cu}$ and $\mathrm{Ag}$ have a specific synergistic effect to stimulate excellent catalytic performance. As a heterogeneous catalyst for PMS activation, $\mathrm{Cu}-\mathrm{Ag} / \mathrm{Ac}$ can degrade phenol under relatively mild conditions. The results show that the degradation efficiency depends on the initial $\mathrm{pH}$, PMS concentration, reaction temperature, and catalyst dosage. Besides, free radical scavenger experiments show that compared with $\cdot \mathrm{OH}, \mathrm{SO}_{4}{ }^{-}$is the main active substance in the oxidative degradation of phenol; the presence of inorganic anions has different effects on the decomposition efficiency of phenol. It can be concluded that the application of $\mathrm{Cu}-\mathrm{Ag} / \mathrm{Ac}$ material with excellent catalytic performance in PMS activation provides a new idea.

\section{References}

1. Wu Y W, Chen X T and Han Y, et al. (2019)Highly Efficient Utilization of $\mathrm{Nano-Fe}(0)$ Embedded in Mesoporous Carbon for Activation of Peroxydisulfate. Environmental Science \& Technology, 53: 9081-9090.

2. Ren W, Xiong L L and Yuan X H, et al. (2019) Activation of Peroxydisulfate on Carbon Nanotubes:

\subsection{Research on reaction mechanism}

The metal Ag participates in the $\mathrm{Cu}(\mathrm{II}) / \mathrm{Cu}(\mathrm{I})$ redox cycle. The exposed $\mathrm{Ag}(\mathrm{I})$ active sites promote the formation of $\mathrm{Cu}(\mathrm{II})$ through the $\mathrm{Ag}-\mathrm{O}-\mathrm{Cu}$ bond, produce $\mathrm{SO}_{4}{ }^{-}$and $\cdot \mathrm{OH}$ in the first stage; the mixed oxidation of two oxidants causes phenol to decompose by ring-opening, forming intermediates such as hydroquinone or catechol. The degradation rate of PMS increases with the increase of $\mathrm{Cu}(\mathrm{II})$ and $\mathrm{Ag}(\mathrm{I})$ doses (Figure 4). The second stage of the reaction is $\mathrm{Cu}(\mathrm{II}) / \mathrm{PMS}$ degrades intermediates into smallmolecule inorganic substances such as $\mathrm{CO}_{2}$ and $\mathrm{H}_{2} \mathrm{O}$. In the $\mathrm{Cu}(\mathrm{II}) / \mathrm{PMS}$ system, the regenerated $\mathrm{Ag}$ is redistributed in the aqueous solution for continuous PMS decomposition[5]. 